\title{
Introduction and Overview of Chapters
}

The economies of East and Southeast Asia have been growing for almost half a century. They are expected to grow amid the slowing down in Chinese and American markets, the uncertainty in the European Union and the United States, the conflicts in the Near and Middle East, and the stagnation in Latin America.

\section{Economic Growth of Emerging East and Southeast Asia}

The almost half a century of high and sustained growth of Asian economies is unprecedented in modern Asian history. In 1979, a report by the Organization of Economic Cooperation and Development (OECD) defined the Newly Industrializing Countries (NICs) as those countries "whose share in world industrial output and in world exports of manufactures has increased rapidly since the early 1960s and particularly during the 1970s" (OECD, 1979, p. 6). Ten NICs were identified in the report: the four "Asian NICs" - South Korea (hereafter, Korea), Taiwan, Singapore, and Hong Kong; Portugal, Spain, Yugoslavia, and Greece in Southern Europe; and Brazil and Mexico in the Americas. After more than a decade, it turned out that only the four NICs in Asia, along with Spain and Portugal, which were already in the OECD group, remained as NICs (WDR, 1992, p. 245). In 1988, during the G7 Summit at Toronto, the four Asian NICs were the only four economies in the world that achieved and maintained long-run rapid modern economic growth, and they were 
renamed as the Newly Industrializing Economies (NIEs). By 1996, Korea was admitted to the OECD. Taiwan should have followed suit, but Taiwan was prevented by the China factor.

The rapid and sustained growth of the NIEs spilled over to China after China opened its coastal cities in 1985, especially after Deng Xiaoping's southern tour in early 1992 (Chapter 2). China quickly joined the group of the NIEs after its admission to the WTO in 2001. The growth trend has also spread to the Southeast Asian countries, especially the ASEAN-4 - Indonesia, Malaysia, Thailand, and the Philippines. They are called the second-generation NIEs (Chapter 4).

In 1993, the World Bank (1993) dubbed the Asian economic growth as The East Asian Miracle. It pointed out that "From 1965 to 1990 the twenty-three economies of East Asia grew faster than all other regions of the world. Most of this achievement is attributable to seemingly miraculous growth in just eight economies": Japan, Korea, Taiwan, Singapore, Hong Kong, and "the three newly industrializing economies (NIEs) of Southeast Asia, Indonesia, Malaysia, and Thailand." It called these eight economies the "HighPerforming Asian Economies" (HPAEs) (World Bank, 1993, p. 1). In this book, we have added China and the Philippines to convert it to 10 economies when we discuss the economic development of emerging East and Southeast Asia (Chapters 3-6), or the economic take-off stage of the Asia-Pacific Region.

Another quarter century has passed since the 1993 study by the World Bank on the "East Asian Miracle," and the "miracle" is continuing according to "Asia's Growth Far from Finished" (Fensom, 2015; Hsiao, 2016). In recent years, their gross domestic product (GDP) and GDP per capita have grown dramatically (Hsiao and Hsiao, 2017, Chapter 9), the economies have shifted to the manufacturing and services, and poverty have been reduced drastically, thanks mainly to the information technology and computer (ITC) revolution (Chapters 4-6). The development has been helped by their strong propensity for learning from the advanced countries, especially from Japan and the United States (Hsiao and Hsiao, 2017). 
In a recent study (Hsiao and Hsiao, 2017, Chapter 9), in terms of GDP per capita in purchasing power parity (PPP), we found that the four Asian NIEs and the four ASEAN countries, along with China and India and, to a lesser degree, Japan, have been growing steadily since 1980, especially Taiwan and Korea. "East Asia and Pacific accounted for almost two-fifths of global growth in 2015, more than twice the combined contribution of all other developing regions" (World Bank, 2016). Their "growth ... is expected to be from 6.5\% in 2015 to $6.3 \%$ in 2016 and 6.2\% in 2017-2018" (World Bank, 2016). Thus, East and Southeast Asia are still the most economically active areas in the world (IMF, 2014), and they are expected to continue to the end of this decade.

In fact, according to the prediction by the Intelligence Unit of The Economist, "Asian economies ... took their share of global GDP from $26 \%$ to $32 \%$ between 2000 and 2014 ... Asia's rise will continue up to $2050 \ldots$, by 2050 it will account for $53 \%$ of global GDP" (EIU, 2015, p. 4).

The rapid and resilient economies and the strategic location of the Asia-Pacific region have attracted the attention of economists, politicians, researchers, and the business community. Many books and journal articles have been written about the economies of the region. The United States is now trading more with Asia than with Europe. The economic dynamics of the ever-growing AsiaPacific region necessitate the United States to adopt a "rebalancing strategy" or "pivot" toward Asia and to propose the Trans-Pacific Partnership (TPP) and the Free Trade Area of Asia-Pacific (FTAAP) before the current US administration.

Although the new Trump Administration decided not to join the TPP or FTAAP, the original members of the TPP, led by Japan, Australia, and Singapore, forged ahead in March 2018 without the participation of the US and formed TPP-11, also known as the Comprehensive and Progressive Agreement for TPP (CPTPP). At the same time, the Trump Administration rolled out the Free and Open Indo-Pacific Strategy (IPS), including India, to promote "free, fair, and reciprocal trade relations." On the other hand, the Chinabacked Regional Comprehensive Economic Partnership (RCEP) was 
launched in 2012 with 16 member countries, but by 2018, it was still in the negotiating stage and evolving slowly.

In any case, the CPTPP, the RCEP, or the IPS are all aimed at opening the economies wider and promoting regional trade and foreign direct investment (FDI) among the member countries for further economic growth. While it is not clear which one will prevail in the future, a new era of the Asia-Pacific economic integration, prosperity, and economic growth through foreign trade and investment is emerging.

\section{Trade, Foreign Direct Investment, and Growth in Open Economic Development}

In the macroeconomics of a closed economy without foreign trade, the economy produces gross domestic product GDP (in US dollars) in a year. GDP is spent by the households (as consumption $(C)$ ), by firms (as investment $(I)$ ), and by government (as government expenditure $(G))$. Thus, GDP $=C+I+G$.

In an open economy, however, the firms also produce for exports $(X)$, and the spending in $C, I$, and $G$ above also includes imported goods and services. We denote the total spending on imported goods and services as $M$. Imports are not produced by the country in question. Therefore, in the foreign sector of the GDP, we deduct imports $M$ from exports $X$ to have net exports $X-M$ and add it to the macroeconomic equation of GDP in an open economy. The net exports, $X-M$, is also called the balance of trade $(B=X-M)$. In developing countries, trade in services is generally very small, that is, statistically not significant. Thus, in this book, we generally consider trade in goods, depending on the data sources.

Furthermore, under an open economy, a country may receive foreign investment $(F)$ to produce goods in the country. Thus, we have

$$
\mathrm{GDP}=C+I+G+F+(X-M) .
$$

In fact, foreign investment consists of direct and indirect foreign investments. Direct foreign investment (DFI) is investment in new facilities or mergers and acquisitions of firms in the hosting countries 
by foreign nationals or firms, while indirect portfolio investment (PI) is foreign investment through purchasing of shares of the hosting country. More accurately, the former is called inward foreign direct investment (IFDI) and the latter is called inward foreign indirect investment (IFII).

Naturally, in an open economy, people in their home country may also invest in a foreign country directly or indirectly. In this case, we have outward foreign direct investment (OFDI) or outward foreign indirect investment (OFII), which is also called outward portfolio investment (OPI).

Since this book deals with the emerging East and Southeast Asia in which stock markets are not developed or are small in the early emerging development stage, and the domestic firms are not large enough, or are still too small, to invest in foreign countries, we only consider inward FDI, namely, IFDI or simply FDI, and denote it as $F$ in the first part of this book.

Thus, in order not to spread our studies too wide and too thin, in the first part of this book, we are interested in the three basic development strategies of the open economies: exports $(X)$, IFDI $(F)$, and economic growth, namely, GDP.

\section{Growth Relations in Open Economic Development}

In the international trade literature, the first three terms on the right-hand side of Eq. (1) is called domestic absorption 11 , where $A$ is given by $A=C+I+G$. Thus, GDP $=A+F+(X-M)$. For simplicity and symmetry, we write GDP as $Y$. Now, taking the total differential on both sides, dividing both sides by $Y$, and rearranging, we have

$$
\frac{d Y}{Y}=\frac{A}{Y} \frac{d A}{A}+\frac{F}{Y} \frac{d F}{F}+\frac{X}{Y} \frac{d X}{X}-\frac{M}{Y} \frac{d M}{M}
$$

\footnotetext{
${ }^{1}$ Goods "absorbed" by domestic expenditure. Thus, the trade balance $X-M$ is the difference of GDP and $(A+F)$, and it will increase if GDP increases faster than domestic absorption and FDI.
} 
where $d$ is differential, $d A / A, d F / F, d X / X$, and $d M / M$ are growth rates of absorption, FDI, exports, and imports, respectively. The coefficient of each growth rate (namely, $A / Y \equiv w_{A}$, $F / Y \equiv w_{F}, X / Y \equiv w_{X}$, and $\left.M / Y \equiv w_{M}\right)$ is the weight of each variable in GDP, and the coefficients sum to 1.

Thus, the growth rate of GDP equals to the weighted average of the growth rates of all the variables, weighted by the proportion of the value of each variable in GDP.

Since $d Y / Y=d \ln Y$, Eq. (2) may also be written as

$$
d \ln Y=w_{A} d \ln A+w_{F} d \ln F+w_{X} d \ln X-w_{M} d \ln M .
$$

For a discrete analysis, the differential $d$ in $d \ln Y$ may be replaced by difference $\Delta$ as $\Delta \ln Y$, where $\Delta \ln Y$ is the logarithmic difference of $Y$ between consecutive time periods (namely, $\Delta \ln Y=$ $\left.\ln Y_{t}-\ln Y_{t-1}\right)$. Similar replacement can be done for the other logarithmic variables $A, F, X$, and $M$. As we will see in this book, this transformation enables us to interpret the results of econometric analysis using vector autoregression (VAR).

For an open economy of a developing country (for that matter, even a developed country), FDI $(F)$ and Trade $(T)$ (in this book, we emphasize exports $(X) 2$ but not imports, $M$, to avoid a collinearity problem in regression analysis, at least for the first approach 3 ) are

\footnotetext{
${ }^{2}$ Note that, as in a macroeconomics textbook, consumption and investment are functions of GNP. The intersection (Keynesian cross) of the supply curve $Y$ on the left and the demand curve on the right determines the equilibrium GDP, $Y$. The left and right variables adjust each other ex ante (before the event) to reach equilibrium, and the impact of $C$ or $X$ on $Y$, for a linear function, is measured by consumption multipliers, etc.

Statistically, the data are ex post (after the event), and the equality of both sides of (1) always holds identically (三). Thus, for the national income account statistics published by the Bureau of Statistics in bookkeeping, both sides of Eq. (1) balance exactly.

${ }^{3}$ Imports of capital goods can indirectly promote technological transfer and economic growth. However, to increase imports, the country must earn foreign currencies from exports. Thus, imports are of secondary importance. Furthermore, since, ideally, imports should be balanced against exports, imports and exports are often linearly correlated, presenting the collinearity problem in econometric analysis. Thus, we consider exports $(X)$ in this book.
} 
considered the important catalysts for economic growth and development. They are commonly called TIG for simplicity. In fact, FDI is regarded as an important means of technological transfer, stimulating domestic investment and human capital development. International trade also stimulates domestic investment, efficient production, and globalization of developing countries. The importance of TIG for open economies, whether developing or developed countries, has been pointed out by various international economic organizations and policy-oriented politicians and economists as evidenced by numerous entries in Google Search or other search engines 4 The topics of the relations among TIG as development strategies are certainly still currently important and up-to-date for all the open economies.

In the studies among TIG, much less known is the reversed relations of the impact of GDP on exports or FDI. Intuitively, by switching the sides of $Y$ and $F$ or $Y$ and $X$, in Eq. (1), that is, making $F$ or $X$ the dependent variable and $Y$ the independent variable, we may also see that the growth of $Y$ also affects the growth of $F$ or $X$. For example, a growing GDP means a growing domestic market or growing industrial activities. This, in turn, will attract inward FDI and increase exports.

\section{Interdependency of the Three Strategies}

Thus, the three variables are mutually interdependent and influence each other. In the jargon of econometrics, there is an endogeneity problem among these three variables, as discussed specifically in detail in Chapter 3. It is not clear which variable influences which variable. We submit that, for the academics as well as for the policy makers, it is important to understand causality and intensity of

\footnotetext{
${ }^{4}$ The importance of trade, investment, and growth (TIG) can be seen from the general discussions and reports on websites. The most recent papers and reports include OECD (2015), Samans and Melendez-Ortiz (2016), Udo (2017), UNESCAP (2017), Eckardt, Mishra, and Dinh (2018), CSEA (2018), Government of Canada (2018), etc. All these recent papers show the importance of the topics of this book. Yet, very few books take up the three variables (TIG) simultaneously and study the interaction of TIG academically using econometric methods of causality analysis.
} 
causality (in terms of statistical significance) among each variable or among a group of variables.

For example, the development policy makers in an open economy need to know which sector to emphasize: the foreign sector (trade and FDI) or the domestic sector (GDP), and among the foreign sectors, which factor to emphasize, trade or FDI. These are the problems of causality and the intensity of causality. Our analysis shows the direction of policy making mostly by using the causality analysis in econometrics.

The policy makers also like to know what the historical trend (time-series) is of each variable in TIG, how each pair of two variables (there are three pairs in TIG) are causally related, and then how all three variables interact with one another, what the intensity or importance of such interaction(s) is, and what the historical trend of these three variables in each and all countries is. Finally, the policy makers also like to know what the causal directions among each of the three pairs of the variables are or what the causal relations among all the three variables are, etc. This is very important information for policy makers or for any economist. To our knowledge, no book deals with these topics systematically directly or indirectly, and uniquely graphically, in the context of development strategies in open economies.

Thus, the main objective of the first part of this book, and the unique contribution of this book, is to analyze the interactions between these three strategic variables for economic development exports, FDI, and GDP, namely, the TIG - empirically as well as theoretically and econometrically in the context of emerging East and Southeast Asian countries.

Naturally, openness may risk economic volatility from other countries. Regional trade and investment can be enhanced by reducing friction and volatility through government-to-government trade agreements or coordination. This is another development strategy of open economies among the emerging countries. The second part of this book introduces the role of the United States in the Asia-Pacific region. We then found that, so far as our data are concerned, the monetary policy coordination among the small and large countries does not work. This theoretical discussion of policy coordination is a 
prelude to the more comprehensive models of free trade agreements (FTA) that were developed later during the last decade of the previous century. After fitting data into the model, we give a plausible justification that monetary policy coordination, to our surprise, does not benefit much for both large and small countries in terms of gain in GDP. The policy makers need to know the problem and its background.

\section{About this Book}

This book is a collection of our papers published mostly during the two decades at the turn of the century (1987-2008), the period economists generally consider the emergence of the Asia-Pacific century and the rapid development of the econometric method of causality. As mentioned above, the major players among countries have been the four Asian NIEs and the Association of Southeast Asian Nations (ASEAN), or ASEAN-4, along with China and Japan. The book covers the economic and econometric analysis of these 10 countries, individually or collectively.

In contrast to the mostly descriptive statistical analysis of the World Bank's The East Asian Miracle (1993) and most of the literature on economic development, we first use the time-series data to present the descriptive data of exports, FDI, and GDP of each country. We then use quantitative and econometric analyses throughout the book systematically, and like the World Bank, we provide future policy implications for economic development based on our econometric analysis of the three strategic variables - namely, exports, FDI, and GDP - taken individually or collectively, for a country or a group of countries.

We examine these three most important macroeconomic variables in open economies, with emphasis on the impacts of ITC revolution (Chapters 3-6). The book shows how other developing countries in other continents, especially those in Africa and Latin America, can learn from the historical experiences of Asian NIEs and ASEAN4 by studying these three strategic variables. It also explores the possibility of policy coordination among East Asian countries with the USA and Japan. 
Since this book is about what we can learn from the historical experiences of emerging Asian NIEs and ASEAN4, the data we use were necessarily taken from the time these countries were "emerging" at various stages of development. Thus, what the book tries to present is "positive economics" (Lipsey, 2008), as well as "normative economics." It is positive economics since what we would like to extract from our analysis are theories and modus operandi which are universal for the emerging open developing countries in this age of globalization, using the historical experiences of Asian NIEs and ASEAN4. As such, our findings should not depend on the specific period of the data we have taken. In other words, the specific time frame of the analysis should not be a problem.

Naturally, the book also presents an aspect of "normative economics," as we would like to rank the importance of economic policies or outcomes for policy recommendations. Thus, this book provides valuable paradigms of economic development for Latin and African countries, and as such, the book is valuable for these emerging developing countries from the economic take-off stage to the mature stage.

Although the chapters were written individually, and the topics were selected based on what we thought were the most important at the time of writing, all chapters are, as explained in the first part of the Introduction and the abstract of each chapter, related to each other very closely and cohesively. They are timely collected in one volume on similar themes for comprehensive understanding of emerging Asian economies, and they are arranged systematically with the level of explanation proceeding from simple to more complex econometric and economic analyses.

For more quantitatively oriented readers or students, we have added new expository appendixes in the book. Thus, this book can also be a supplement to the World Bank's book or any textbook on economic growth and development. As such, it can be a textbook or a reference for graduate or upper undergraduate courses in economics, business, quantitative analysis, applied econometrics, and as a reference for researchers and policy makers at various stages of research. 
The book is unique as it provides the first quantitative and comparative analyses of regional economies, economic growth, real and financial linkages, and causality among the strategic economic variables of the open economies in the Asia-Pacific region.

Moreover, countries may invigorate exports and FDI through better cooperation among governments, like current FTA or regional trade agreements like the TPP or the RCEP, which were non-existent or not popular during the writing of these chapters. As a prelude to trade agreements, we have explored the possibility of monetary policy coordination among East Asian countries with the USA and Japan. We believe we have derived a plausible interpretation of why policy coordination was not popular or even possible. Thus, the book will also contribute to the scholarship on the regional studies and cooperation of East and Southeast Asia.

The time-series analysis presented in the book includes unit root tests, cointegration, error correction, Granger causality tests, Sims' exogeneity test, and panel data analysis along with the descriptive statistics. These topics were new (advanced) in econometrics at the time of our writing. They are now standard subjects in many, if not all, undergraduate and introductory graduate econometrics classes as evidenced in Dougherty (2007), Gujarati and Porter (2010), Hill, Carter, Griffiths, and Judge (2000), and Woodridge (2003).

As with any statistical/econometric studies, some of the statistical tests are based on the large sample properties (like the $t$-test of significance of a sample mean with the unknown population variance), and the studies require a large sample. This is impossible for macroeconomic data like those on GDP, FDI, exports, and imports, etc. Thus, the readers should be aware of the assumptions and limitations made on the econometric analysis and the interpretation of the test results. Nevertheless, it appears that our test results in this book generally yield very reasonable policy interpretations consistent with our economic reasoning and the actual observations.

In each chapter, as shown by the sections inside the chapter, the first several sections explain the relevant economic conditions in detail, with extensive literature review, to enable the reader's understanding of the background of the countries and the objectives 
of the chapter. We then explain the need for the use of certain econometric models and the sources of data in detail. Finally, we illustrate the results of quantitative analysis graphically, acknowledging the limits of the model and analysis. The conclusion then explores policy implications of the analysis.

For some inquisitive readers, we have redrawn figures and tables in this book so that they are more user-friendly, and we have added several expository notes in the appendixes of this book to help readers understand the methods of mathematical derivation. While the quantitative analysis used in several chapters of this book requires a certain level of econometrics and mathematics, the readers who are not interested in the quantitative analysis may quickly glance over the quantitative part and go directly to the concluding remarks on policy implications of the chapter without a loss of understanding.

This is the third book in the sequel of our research on Asian Economic Development. We started from the country study of Economic Development of Taiwan: Early Experiences and the Pacific Trade Triangle (Hsiao and Hsiao, 2015). We expanded our analysis to Economic Development of Emerging East Asia: Catching up of Taiwan and South Korea (Hsiao and Hsiao, 2017), dealing with the long-run catching up process and convergence of the two newly developed countries in East Asia to Japan and the United States. This book then extends our previous two studies from economic development of emerging East Asia to that of emerging East and Southeast Asia, with emphasis on macroeconomic development strategies and policy implications of open economies.

As in the previous volumes, for those who are interested in our econometric analysis, we provide the detailed sources of data and references in each chapter. All the tables and figures are constructed using Microsoft Excel. We believe that the various methods and arrangements of statistical data into Excel tables and figures in this book are also unique and innovative.

The econometrics software programs used in this book were the EViews software (see www.EViews.com/home.html) for the first six chapters and the Micro TSP program (version 7) for Chapters 7 and 8. Naturally, EViews may also be used for these two chapters. 
Some data sources may not be readily accessible or even be available. For practice and practical purposes, data can be easily generated by using the methods in Hsiao (2011, pp. 182, 350, 494, 526) applying the random number generating function from the widely and easily available Microsoft Excel program and by referring to the descriptive statistics given in the chapter.

\section{Overview of Chapters}

\section{Part I. Emerging East and Southeast Asian Economies - Exports, FDI, and Growth}

The first half of the book analyzes the interdependence and interaction among trade/exports, FDI, and economic growth (TIG) of the East and Southeast Asian countries. The second half discusses the role of the United States in Asia and the possibility of policy coordination between the USA and the East Asian countries in this interdependent world.

It is well known that Korea and Taiwan are two countries that had similar historical background before World War II, and developed very closely and rapidly after the war (Hsiao and Hsiao, 2017). It is often claimed that the rapid growth of these two countries has benefited from the export-promotion policy, namely that exports cause economic growth through their impact on the GDP. On the other hand, there are also studies indicating economic growth itself promotes exports, as higher GDP will stimulate imports, and to pay for imports, a country must increase exports to earn the foreign currencies. Hence, the causality between exports and economic growth is one of the controversies in economics.

In this book, we first explore the causality (to be precise, Granger causality, see Appendix 3B of Chapter 3) between exports and economic growth among the Asian NICs in Chapter 1. In fact, Chapter 1 is one of the very early papers in the economic literature, which applies causality and exogeneity tests between exports and GDP for Asian NICs. The Sims' exogeneity test shows that, unlike the general perception that exports may unidirectionally cause GDP, 
there is a strong bidirectional causality between exports and GDP, indicating both factors influence each other.

In addition to exports strategy, the other important external factor influencing economic growth is inward FDI. It is also an important strategy to promote economic development. There is a vast amount of literature discussing the pros and cons of encouraging FDI to promote economic growth. In view of the importance of FDI in China in the 1990s, Chapter 2 uses panel data to analyze why FDI was attracted, especially from Asian NICs (Korea, Taiwan, Hong Kong, and Singapore) and Japan, to China despite several negative predictions of China's future, while other countries were starving for FDI (thus, we call China a "strange attractor" of FDI).

Few readers are aware of the fact that at the beginning of the Chinese development, FDI in China depended on small- and mediumsized enterprises (SMEs) from Taiwan and Hong Kong, not the large companies from the USA and EU (we submit this observation was new). However, the FDI from Asian NIEs were very small, especially the FDI from Taiwan, which was only US $\$ 1$ million per case. This implies that, as per development policy, a developing country should not be biased against, or even exclude, small-scale FDI.

On the other hand, we also show in Chapter 2 why Taiwanese investment in China was rational, as it was the smallest per case among other countries. Thus, the Taiwanese FDI took into account its political risk in China, implying the rational expectation of the Taiwanese firms. We also discussed the cultural similarity and geological proximity, and we use panel data analysis to verify our observations.

It is natural to combine these three strategic variables discussed in the previous two chapters - exports, FDI, and GDP, namely, TIG, the three basic macroeconomic variables - simultaneously in an econometric model. This will give us a better picture of the role and interaction of these macroeconomic variables. Chapter 3 studies all three variables systematically for eight emerging East and Southeast Asian economies (China, Korea, Taiwan, Hong Kong, Singapore, Malaysia, the Philippines, and Thailand). After examining the interactions among these three variables in each country, we use 
both time-series analysis and panel data analysis to compare the results.

The results indicate that since the time-series analysis of each country gives vastly different Granger causality relations, so we conclude that the panel data causality analysis is a superior method of analysis. We also found very useful policy implications from our analysis. In the appendixes of this chapter, for the first time in the economic literature, we give a macroeconomic foundation of using a VAR analysis with regard to TIG, and we explain it in detail along with the method of Granger causality in the appendixes.

Instead of examining individual countries, the econometric analysis may use panel data causality analysis for groups of East and Southeast Asian countries. Noting the different developmental stages of these economies, Chapter 4 supplements the three-variable panel data causality analysis of Chapter 3 to seven Asia-Pacific ANIEs. This is accomplished by constructing a panel of the first-generation ANIEs (Taiwan, Korea, and Singapore) and a panel of the secondgeneration ANIEs (Malaysia, the Philippines, Thailand, and China). We then combine the two panels into one panel.

The panel VAR Granger causality tests show that the firstgeneration ANIEs have bidirectional causality relations for all three strategic variables, but only weak causality relations between exports and GDP for the second-generation ANIEs. Thus, we conclude that the stage of development does matter in the causality relations among the three variables. As such, a different government policy is required. The policy implication from this analysis is that the developing country should adopt the export-promotion policy before encouraging inward foreign investment promotion policy.

Chapter 5 extends and expands the analysis of previous chapters and studies the impact of the recent IT revolution on the New Economy of the three Asian NICs, namely, Taiwan, Korea, and Singapore. Here, the economies have interacted with each other through the real linkages of exports and FDI, and they have also interacted through the financial linkage of stock prices. Instead of using the level or the first differences, the model uses volatilities of seven macroeconomic variables: GDP, stock price index, consumer 
price index, exchange rate, interest rate, narrow money supply (M1), and merchandise exports. The volatilities of variables are measured by the square roots of conditional variances that are generated by the Generalized Autoregressive Conditional Heteroskedasticity (ARCH/GARCH) procedure.

While we have found that the causality among variables differs among countries, the panel data analysis indicates that stock market volatility can cause instability of the exchange rate, GDP, and money supply. Thus, the important policy implication of this finding is that, instead of using the classical thinking of money and finance as a "veil," the government should pay closer attention to the international impact of stock markets.

\section{Part II. The United States and Emerging East and Southeast Asia}

The bulk of the US foreign trade has shifted from Europe to Asia during the past two decades. The US trade and investment play an important role in Asia. The US initiation of "rebalancing" in the Asia-Pacific region of the last US administration and recent trade dispute between the USA and China indicate the importance of this region for the USA and the world economy. Hence, studies of the East and Southeast Asian economies and politics could not ignore the impact of the US economy on Asia-Pacific economies. This is another area, in addition to the impact of the recent IT revolution, the 1993 World Bank study needed to emphasize. Hence, Chapters 68 in Part II of this book examine the role of the USA in the AsiaPacific economies and the possibility of policy coordination between the emerging small countries, Taiwan and Korea, and the developed large countries, the US and Japan in Asia.

Chapter 6 evaluates the interdependence between the US economy and Asian economies due to the recent IT revolution. Our tests of four countries - Taiwan, Korea, Japan, and China — show no significant unidirectional causality from the US GDP to that of the four countries, but the US stock price will cause stock market instability in these countries except China. Thus, in general, 
government stabilization policy in these Asian countries should pay close attention to the external impact from the USA on the stock market, which academic economists tend to ignore.

In view of the spread of instability among nations in this interrelated and interactive world, in an ideal situation, a country may want to coordinate its economic policy with that of the other countries to mitigate, or even eliminate, economic instability, and all countries could reap benefits. Thus, Chapters 7 and 8 introduce a Mundell-Fleming-Dornbusch type two-country game-theoretic model to examine the gain from monetary policy coordination. This is done first between Taiwan and the United States (Chapter 7). We then expand the method in Chapter 7 to study the effect of policy coordination between Taiwan and Korea (small countries) on the one hand and Japan and the United States (large countries) on the other (Chapter 8). We would like to know whether small countries and/or the large countries can benefit from economic policy coordination.

Chapters 7 and 8 present our game-theoretic empirical studies, which are unique in the literature in terms of the theoretical model, country studies, and econometric and simulation analysis. Our results show that policy coordination does not benefit small countries and seems to have no effect for large countries. The results are similar in a larger model in Chapter 8 when we consider a group of small countries (represented by Taiwan and South Korea) and large countries (represented by the United States and Japan). Our analysis gives a plausible justification that monetary policy coordination does not benefit much for both large and small countries in terms of gain in GDP. The policy makers need to know why. Thus, while more studies are needed, it appears that the neoclassical free competition among countries may still be the best modus operandi for all the countries.

Since our research was done some decades ago, the last chapter, Chapter 9, re-evaluates our research results from broader vantage points of current global economy as well as the evolution of economic policy and recent advancement of development strategies and financial development. We show that the results of our research on development strategies of open economies based on the emerging East 
and Southeast Asia are still very much applicable and illuminative for the researchers and policy makers in this age of globalization.

We have shown the sequence of our studies and their interrelation among the chapters in this Introduction. The topics presented in this book are strongly policy-oriented. Our policy analysis is statistically rigorous, based on statistical inference. The beginning of each chapter has a more detailed abstract of the contents. For students and young researchers, this book may serve as an example of writing research papers in regional studies, as we have received many requests for more information and questions about the papers collected in this volume, especially those in Part I on the time-series and panel data analysis.

\section{References}

CSEA (2018). Research Area: Trade, Investment and Growth (TIG), The Center for the Study of the Economies of Africa (CSEA) downloaded in June 2018 from http://cseaafrica.org/trade-investment-and-growth-tig/.

Dougherty, Christopher (2007). Introduction to Econometrics (3rd edn., Chapters 12-14). London: Oxford University Press.

Eckardt, Sebastian, Deepak Mishra, and Viet Tuan Dinh (2018). Vietnam's manufacturing miracle: Lessons for developing countries, Brookings Institute. Downloaded in June 2018 from https://www.brookings.edu/blog/futuredevelopment/2018/04/17/vietnams-manufacturing-miracle-lessons-for-deve loping-countries/

Economist Intelligence Unit (EIU) (2015). Long-term Macroeconomic Forecasts, Key Trends to 2050. A Special Report from the Economist Intelligence Unit. Downloaded on 30 July 2016, from http://pages.eiu.com/rs/783 XMC194/images/LongtermMacroeconomicForecasts_KeyTrends.pdf. Relocated to https://espas.secure.europarl.europa.eu/orbis/sites/default/files/g enerated/document/en/Long-termMacroeconomicForecasts_KeyTrends.pdf (January, 2020).

Fensom, Anthony (2015). Asia's Growth Far from Finished: The Region Is Still the World's Engine of Economic Growth. The Diplomat, 12 August 2015. Based on an interview with Duncan-Innes Ker of EIU. Downloaded in July 2016 from the website, http://thediplomat.com/2015/08/asias-growth-far-f rom-finished/.

Government of Canada (2018). Canada-Asia Trade and Investment for Growth Program, downloaded in June 2018, from http://international.gc.ca/world -monde/issues_development-enjeux_developpement/priorities-priorites/whe re-ou/brochure.aspx?lang=eng.

Gujarati, Damodar N. and Dawn C. Porter (2010). Essentials of Econometrics (4th edn., Chapter 12). New York, NY: McGraw-Hill Irwin. 
Hill, R. Carter, William E. Griffiths and George G. Judge (2000). Undergraduate Econometrics (2nd edn., Chapters 16 and 17). New York, NY: John Wiley \& Sons, Inc.

Hsiao, Frank S. T. (2011). Economic and Business Analysis: Quantitative Methods using Spreadsheets. Singapore: World Scientific Publishing.

Hsiao, Frank S. T. (2016). How Bad Is Taiwan's Economy? Compared to other Economies around the World, Taiwan is doing just fine. Featured Article in The Diplomat, 22 July. Downloaded in August 2018 from https://thediplom at.com/2016/07/how-bad-is-taiwans-economy/.

Hsiao, Frank S. T. and Mei-Chu Wang Hsiao (2015). Economic Development of Taiwan-Early Experiences and the Pacific Trade Triangle. Singapore: World Scientific Publishing, 600 pp.

Hsiao, Frank S. T. and Mei-Chu Wang Hsiao (2017). Economic Development of Emerging East Asia-Catching Up of Taiwan and South Korea. London: Anthem Press, 326 pp; Cambridge University Press Cambridge Core 2018.

IMF (2014). Regional Economic Outlook: Asia and Pacific-Sustaining the Momentum: Vigilance and Reforms. Washington, D.C.: International Monetary Fund. Downloaded in May 2015 from http://www.imf.org/ external/pubs/ft/reo/2014/apd/eng/areo0414.htm Relocated to https:// www.imf.org/en/Publications/REO/APAC/Issues/2017/02/23/Sustainingthe-Momentum-Vigilance-and-Reforms (January, 2020).

Lipsey, Richard G. (2008). Positive economics. In The New Palgrave Dictionary of Economics (2nd edn.), L. E. Blume and S. N. Durlauf (Eds.). London: Palgrave Macmillan.

OECD (1979). The Impact of the Newly Industrializing Countries on Production and Trade in Manufactures. Report by the Secretary-General. Paris: OECD.

OECD (2015). How to connect trade, investment and development. OECD Forum. Downloaded in June 2018, from http://www.oecd.org/trade/connect-tradeinvestment-development.htm. Relocated to http://www.oecd.org/forum/oe cdyearbook/connect-trade-investment-development.htm|(January, 2020).

Samans, Richard and Ricardo Melendez-Ortiz (2016). How can trade and investment underpin growth? World Economic Forum. 22 January 2016. Downloaded in November 2017 from https://www.weforum.org/agenda/2 016/01/a-new-agenda-for-global-growth-through-trade-and-investment.

Udo, Bassey (2017). ECOWAS, WTO urge more trade, investment for economic growth. 3 November Premium Times, 25 June 2018. (ECOWAS, Economic Community of West African States). Downloaded in June 2018 from https://www.premiumtimesng.com/business/business-news/248269-ec owas-wto- urge-trade-investment-economic-growth.html.

UNESCAP (2017). Asia-Pacific Trade and Investment Report: Channeling Trade and Investment into Sustainable Development. NY: United Nations Economic and Social Commission for Asia and the Pacific. Downloaded in June 2018 from https://www.unescap.org/publications/APTIR2017.

Woodridge, Jeffrey M. (2003). Introductory Econometrics, A Modern Approach (Chapter 18). Ohio: Thompson/South Western.

World Bank (1992). World Development Report, 1992. London: Oxford University Press. 
World Bank (1993). The East Asian Miracle, Economic Growth and Public Policy, A World Bank Policy Research Report. London: Oxford University Press.

World Bank (2016). East Asia-Pacific Economic Update, April 2016: Growing Challenges. Key findings, downloaded in July 2016 from the website http://www.worldbank.org/en/region/eap/publication/east-asia-pa cific-economic-update. Relocated to https://openknowledge.worldbank.org/ bitstream/handle/10986/24015/9781464809064.pdf (January, 2020). 